\title{
O MOVIMENTO EDUCACIONAL INDÍGENA NO BRASIL E SEU DESDOBRAMENTO NO AMAPÁ (1988-2002): CAMINHOS E DESCAMINHOS ${ }^{1}$
}

The indigenous educational movement in Brazil and its development in Amapá (1988-2002): pathways and embezzlement ${ }^{2}$

Pollianna Pimentel Ferreira*

Resumo: Este trabalho busca analisar o movimento de construção da Educação Escolar Indígena no Brasil e no estado do Amapá, pondo em evidência as discussões antes da Constituição Federal de 1988 e após sua promulgação. Sua justificativa advém da necessidade de compreensão das bases históricas conceituais, organizacionais e legais por fundamentar e explicar a Educação Escolar Indígena no País. Tendo como questionamentos motivadores: as leis nacionais e os programas estaduais “constroem” uma Educação Escolar Indígena ou uma Educação Escolar para o indígena? As leis estão sendo respeitadas nas escolas das aldeias do estado do Amapá ou a escola implantada ainda segue os padrões da escola do não índio? Metodologicamente, o trabalho foi pautado na análise de documentos e teve como referência bibliografias basilares sobre a temática. A pesquisa apontou os ganhos educacionais, mas também confirmou as dificuldades encontradas pelas populações nativas para consolidar e fazer acontecer a Educação Escolar Intercultural.

Palavras-chave: Educação Escolar Indígena; Educação Escolar Intercultural; Amapá.

Abstract: This work aims to analyze the construction movement of Indigenous School Education in Brazil and in the state of Amapá, highlighting the discussions before the Federal Constitution of 1988 and after its promulgation. Its justification comes from the need to understand the historical, conceptual, organizational and legal bases that underlie and explain Indigenous School Education in the Country. Thus, the questions that moved it were: national laws and state programs "construct" an Indigenous School Education or a School Education for the indigenous? Are laws being respected in village schools in the state of Amapá, or is the school implemented still following the standards of the non-Indian school? Methodologically, the work was based on the analysis of documents and had as reference basic bibliographies on the subject. Therefore, the work pointed to the educational gains, but confirmed the difficulties encountered by native populations to consolidate and make Intercultural School Education happen.

Keywords: Indigenous School Education; Intercultural School Education; Amapá.

\section{INTRODUÇÃO}

O movimento indígena, que traz em seu bojo, conforme Munduruku (2012), um caráter educativo origina-se e desenvolve-se adjacente a acontecimentos sociais eclodidos nos anos de 1970, momento em que o governo militar esteve em pleno desenvolvimento no país. Dessa

\footnotetext{
${ }^{1}$ Desdobramento do Trabalho de conclusão do Curso de Especialização em História e Historiografia da Amazônia, pela Universidade Federal do Amapá - UNIFAP, no ano de 2015, sob a orientação da Professora Dra . Cecília Maria Chaves Brito Bastos.

${ }^{2}$ Completion of the Specialization Course on History and Historiography of the Amazon, by the Federal University of Amapá - UNIFAP, in the year 2015, under the guidance of Professor Cecília Maria Chaves Brito Bastos.

* Mestranda do Programa de Pós-Graduação em Educação na Linha de Políticas Educacionais, pela Universidade Federal do Amapá (UNIFAP)
} 
forma fica evidente que as lutas e o surgimento das lideranças indígenas que entram em cena por seus direitos nos anos de 1980, compõem batalhas pretéritas e os ganhos obtidos com a Constituição Federal de 1988 são frutos das reivindicações e discussões que já aconteciam em prol de uma educação específica e diferenciada para esses povos.

A educação escolar indígena e para os indígenas passou a ocupar uma pauta política expressiva no movimento nativo e de seus apoiadores em nível nacional, com posterior desdobramento local. Essa temática ganhou autoridade à medida que movimentou os mais diversos atores sociais, estabelecimentos públicos e particulares, bem como seus recursos para a implantação e execução de escolas diferenciadas em áreas indígenas por todo Brasil (GRUPIONI, 2014).

Nesse sentido a política e a educação são compartes para as conquistas que compreendem a legislação educacional indígena, fomentada principalmente a partir da $\mathrm{CF} / 88$. A escola indígena foi inserida no sistema educacional nacional com predicados particulares como o uso da língua materna, sistematização de conhecimentos e saberes tradicionais, com a atuação de professores índios, calendário adaptado ao seu cotidiano e rituais, a elaboração dos currículos diferenciados e com a comunidade participando efetivamente na busca dos objetivos e rumos da escola (GRUPIONI, 2014, p. 1). No entanto, não há um preceito estruturado que consinta e supra na íntegra os imperativos educacionais indígenas, devido a uma intrínseca divergência na constituição e efetivação do ser e fazer da educação escolar nas aldeias.

Desse modo, o presente trabalho busca apresentar as formas de educação impostas aos nativos preponderantes para certa "destruição cultural" e física desses povos desde a colonização, compreendendo como o movimento indígena começou sua organização no Brasil na forma de resistência à dominação imposta pelos não índios; expor os ganhos constitucionais para esses povos, enfatizando a questão educacional escolar e as leis subsequentes que tiveram a CF/88 como base para seu nascimento; e, por fim, demonstrar os desdobramentos do movimento nacional especificamente no estado do Amapá, no intento de perceber os seus caminhos e descaminhos na construção da educação escolar indígena amapaense.

Para tanto, os documentos analisados estavam disponíveis na Secretaria de Estado de Educação do Amapá (Seed) e no Núcleo de Educação Indígena (Nei), a saber: a Proposta Curricular Karipuna e Galibi-Marworno e o Projeto do Programa de Etno-Educação Indígena do Estado do Amapá. O Projeto Político Pedagógico do Curso Intercultural Indígena da Universidade Federal do Amapá (Unifap) foi disponibilizado pela Instituição. O levantamento bibliográfico foi realizado na Biblioteca Central da Unifap e no Curso de Cultura e História dos Povos Indígenas do Amapá e Norte do Pará, ofertado pela Unifap/UAB em 2011. Contou-se 
com a internet para acesso à Lei de Diretrizes e Bases da Educação (LDB/96); ao Referencial Curricular para as Escolas indígenas (Rcnei/98); às Diretrizes Curriculares Nacionais da Educação Escolar Indígena/99 e ao Plano Nacional de Educação (PNE/01).

Essas fontes foram analisadas à luz da pesquisa documental, método apontado nas concepções de Evangelista (2014), que procura articular elementos teóricos-metodológicos que possibilitam a compreensão de processos de produção, principalmente no que contemple as diretrizes políticas educacionais, presentes em documentos oficiais e oficiosos divulgados em papel ou eletrônicos. Esses passos resultantes de intencionalidades para além da pesquisa (EVANGELISTA, 2014), foram determinantes e fecundos para discutir, elucidar, desconstruir compreensões do mundo, mas também produzir documentos, conhecimentos e consciências.

Destarte, buscou-se inquietar todos os envolvidos com a questão educacional para que contribuam positivamente para a consolidação da educação intercultural dando enfoque ao estado do Amapá, respeitando as diferenças culturais e sociais de cada comunidade, seja ela índia ou não-índia, pois a história de cada um desses sujeitos integra a história do país.

\section{BREVE HISTÓRICO DA EDUCAÇÃO ESCOLAR INDÍGENA ANTES DA CONSTITUIÇÃO FEDERAL DE 1988 E SEUS PARADGMAS}

A educação para os indígenas antes da CF/88 é debatida por diversos autores como Bello (2001), Ribeiro (2004) e Saviani (2013), por exemplo. Para Bello (2001), a educação iniciada pelos colonizadores traz uma característica peculiar, uma educação de rupturas, pois quando os portugueses trouxeram o seu padrão próprio de educação da Europa desconsideraram os modos de fazer educação dos povos indígenas, aí se teve a primeira grande protrusão.

Nesse sentido, a primeira etapa das ideias pedagógicas no Brasil está entre 1549 e 1759, considerado o "período heroico", com forte monopólio da vertente religiosa da pedagogia tradicional em que o projeto de colonização e ocupação do Brasil esteve com envolvimento maior da monarquia a partir da instituição de um governo geral comandado por Tomé de Sousa. O ano de 1549 marca a chegada dos jesuítas chefiados por Manoel da Nóbrega com a missão de converter os gentios, ou seja, a ocupação é justificada enquanto uma missão religiosa. Destarte, a inserção do Brasil no chamado mundo ocidental se deu através de três aspectos articulados, mas não harmônicos: colonização, educação e a catequese. (SAVIANI, 2013).

Nas terras brasileiras, os jesuítas se dedicaram à pregação da fé católica e ao trabalho educativo, pois perceberam que não conseguiriam converter os índios a fé católica sem que eles soubessem ler e escrever. (BELLO, 2001). De 1760-1808, após expulsar os Jesuítas, Pombal retira a prática educativa do campo do proselitismo e do noviciado e a molda para reerguer 
Portugal da falência que se encontrava diante das demais potências europeias da época. A educação passa a ser organizada para servir aos interesses do Estado. (BELLO, 2001).

Desse modo, o período colonial e o império brasileiro são marcados por evidenciar as populações indígenas como objetos de discórdias, como entraves à expansão política e social e utilização da educação europeia como forma de massacre dos valores culturais e educacionais próprios dos nativos, caracterizando assim, o paradigma exterminacionista. Porém, até o século XIX existe um deslocamento de interesses e cobiça do colonizador somados às ações da Igreja, à política indigenista do Governo Colonial e, posteriormente do Governo Imperial, que desvaneceu da face da terra "quase a totalidade dos habitantes do chamado Novo Mundo, sob o entendimento de que a política de extermínio consistia no combate à barbárie e constituía-se em premissa para o desenvolvimento da civilização.” (BELFOR, 2006, p. 14-15).

Em uma outra perspectiva o século XX surge num repensar dessas ações e relações com os povos indígenas baseadas no etnocentrismo e "abre espaço" para a concepção do ser indígena em sua diversidade cultural, étnica e linguística, assegurados pelo paradigma integracionista. Este segundo modelo de política indigenista é caracterizado pela percepção de que os povos indígenas, suas culturas, suas formas de organização social, suas crenças, seus modos de educar e de viver eram inferiores aos dos colonizadores europeus, estando fadados à dissipação. Essa visão do índio, enquanto ser "baixo", sujeitou-os à qualidade de indivíduos estimados incapazes à tutela orfanológica, prevista na Lei de 27 de outubro de $1831^{3}$ e, baseado na legislação da tutela, busca protegê-los e "prover seu sustento, ensinar-lhes um ofício e, assim, 'integrar' aqueles que foram retirados do convívio de suas culturas tradicionais à sociedade nacional." (SOUZA FILHO apud MUNDURUKU, 2012, p. 30-31).

O integracionismo faz parte do governo republicano ao qual não é mais interessante exterminar, e sim integrar os nativos aos padrões sociais estabelecidos. Firmado nessas bases foi criado o Serviço de Proteção ao Índio (SPI) em 1910 e posteriormente a Fundação Nacional do Índio (FUNAI) em 1967, como forma de "intervenção salvadora do governo" que livraria os indígenas da extrema penúria e perseguição inclemente a que foram submetidos no esforço de "confraternizar" com o branco. Esses dois órgãos foram criados com o objetivo de gerenciar os povos indígenas e os integrar à nação, dentro das formas de administração colonial

\footnotetext{
${ }^{3}$ Art. $1^{\circ}$ Fica revogada a carta Régia de 5 de novembro de 1808, na parte que mandou declarar guerra aos índios bugres da província de São Paulo, e determinou que os prisioneiros fossem obrigados a servir por 15 anos os milicianos ou moradores que os prendessem. Art. $2^{\circ}$ Ficam também revogadas as Cartas Régias de 13 de maio e de 2 de dezembro de 1808, na parte que autorizam na província de Minas Gerais a mesma guerra e servidão dos índios prisioneiros. Art. $3^{\circ}$ Os índios todos até aqui em servidão serão dela exonerados. Art. $4^{\circ}$ Serão considerados como órfãos e entregue aos respectivos Juízes para lhes aplicarem as providencias da ordenação. (BELFOR, 2006, p. 15).
} 
empregados desde os tempos dos missionários jesuítas, com postos semelhantes aos aldeamentos construídos desde o século XIX. (RIBEIRO apud MUNDURUKU, 2012).

Conforme Oliveira e Freire (2006, p. 124), no início do século XX, muitos indígenas passaram a instituir e adotar cerimônias cívicas nas quais se cultuava a pátria através do hasteamento da bandeira nacional e o canto de hinos oficiais e militares. Com intuito de "nacionalização" dos nativos por meio da educação os autores asseguram ainda que:

Dos antigos aldeamentos missionários aos postos indígenas do SPI, passando pelos índios contatados pela Comissão Rondon, a alfabetização de crianças e adultos procurava consolidar a sedentarização de um povo indígena. Era parte de um processo pedagógico que envolvia esses cultos cívicos, e o aprendizado de trabalhos manuais, da pecuária e de novas práticas agrícolas. Envolvia também novos cuidados corporais, como o uso de vestimentas e o aprendizado de práticas higiênicas.

Desde o seu início o SPI investia na educação como instrumento transformador dos índios em trabalhadores nacionais, porém, essa escolarização foi dizimando-os culturalmente, haja vista que as escolas dos postos indígenas não se diferenciavam das escolas rurais, sendo utilizado o mesmo método de ensino precário e falta de formação dos professores. Todo o material didático utilizado e a alfabetização artesanal não permitiam qualquer reformulação da educação, menos ainda, uma tangencial valorização da cultura própria desses povos.

Segundo Cunha (2012), o SPI extingue-se melancolicamente em 1966 em meio a acusações de corrupção e, seguindo com a política indigenista, desde 1967, a Funai passou a ser o órgão oficial responsável pela promoção e proteção aos direitos dos povos indígenas de todo o país. Nesse sentido, a Funai passou a ter competência para estabelecer as diretrizes e a segurança do cumprimento da política indigenista, bem como a gestão do patrimônio indígena, sua conservação, ampliação e valorização. De acordo com Munduruku (2012, p. 34-35):

Inicialmente, a FUNAI teve à sua disposição todas as condições necessárias a uma boa atuação: recursos orçamentários suficientes, renovação dos recursos humanos, eliminação dos funcionários corrompidos e a criação de condições legais mais eficientes na proteção dos povos indígenas. Contudo, permaneceu sob direção militar, tornou mais centralizada sua estrutura burocrática, deixou de dar continuidade à qualificação de recursos humanos e permitiu a ocupação de cargos por pessoas descomprometidas e despreparadas para com o trabalho indigenista, além de omitir-se a assegurar a posse e usufruto exclusivo dos territórios indígenas, cujo programa de demarcação resultou lesivo, pois tolerou a ocupação ilegal das terras.

Dessa forma, a política indigenista permanece ligada ao Estado e as suas necessidades e prioridades, designada a continuar o exercício da tutela do Estado sobre os índios a Funai, 
asseguram Oliveira e Freire (2006), tem os seus princípios de ação fundamentados no mesmo paradoxo fundador do SPI: o 'respeito à pessoa do índio e às instituições e comunidades tribais' associado à 'aculturação espontânea do índio' e à promoção da 'educação de base apropriada do índio visando sua progressiva integração na sociedade nacional'. Ou seja, em termos práticos, o respeito à cultura indígena, assim como na época do SPI, estava subordinado à necessidade de integração e o estímulo à mudança - aculturação - como política que prevaleceria para os povos indígenas também sob o comando da Funai.

A partir de 1970 experiências de educação indígena diferenciada efetivaram-se no Brasil. Essas experiências ganharam reconhecimento jurídico e estatal com a $\mathrm{CF} / 88$ e as legislações específicas que a seguiram. Cita-se assim o art. 231 da CF/88, o qual além de ordenar a demarcação dos territórios indígenas, estabelece saúde e educação distinguidas, volvidas para a cultura e para as necessidades reais dos indígenas. No fim da década de 70 e início da de 80, pela primeira vez, se institui um movimento indígena de âmbito nacional. Essa mobilização esclarece as novidades obtidas na Constituição de 1988, que abdica os desígnios e o jargão assimilacionistas e perfilha os direitos naturais dos índios, seus direitos históricos, à posse da terra de que foram os primeiros senhores (CUNHA, 2012).

Portanto, a singularidade indígena considerada "bizarra" esteve mil vezes ameaçada pelo extermínio e posterior intuito de integração. Mas, entre lutas, guerras, perdas humanas e culturais, a característica própria do índio conseguiu sobreviver, inaugurando após a $\mathrm{CF} / 88$ o novo paradigma nacional, o Interacionista, que será abordado na sessão seguinte.

\section{O CENÁRIO EDUCACIONAL INDÍGENA NO BRASIL APÓS A PROMULGAÇÃO DA CONSTITUIÇÃO FEDERAL DE 1988}

Com a promulgação da $\mathrm{CF} / 88$ inaugura-se uma nova fase do movimento com transformações significativas na forma política e jurídica de introdução das populações indígenas no Estado brasileiro. A C.F/88 garantiu aos índios o amparo do cultivo a sua alteridade cultural e instituiu como obrigação do Estado a tarefa de resguardar estes grupos. Os indígenas, de forma pioneira na história da educação de nosso país serão parte de uma política educacional baseada nos princípios de respeito à diversidade étnica e cultural de seus grupos e reconhecimento dos saberes tradicionais, transmitidos ao longo de muitas gerações.

Assim, corroborando para efetivação e valorização dos direitos indígenas a serem garantidos, o art. 215. $\S 1$ da CF/88, relata que o Estado garantirá a todos o pleno exercício dos direitos culturais e acesso às fontes da cultura nacional, apoiará e incentivará a valorização e a difusão das manifestações culturais". Logo nesta categoria, as manifestações culturais 
populares indígenas e afro-brasileiras, entram em pauta e ganham reconhecimento no cenário nacional, em um novo paradigma, o interacionista.

As propostas para uma educação indígena diferenciada dos padrões não índios estão presentes no art., $210, \S 2^{\circ}$, que alude sobre as questões educacionais voltadas para a educação indígena, considerando propostas de ensino que valorize a cultura, a língua, formação e conteúdo específicos para cada modalidade de ensino, promovendo assim a garantia de reforçar os direitos indígenas a uma educação de qualidade no sentido amplo de sua compreensão, isto é, preparar dentro do cenário educacional brasileiro o futuro do cidadão indígena e não indígena para o convívio positivo e pacífico na inter-relação social com a sociedade nacional. Para tanto, evidencia-se que (BRASIL, 1988, p. 57):

Art. 210. Serão fixados conteúdos mínimos para o ensino fundamental, de maneira a assegurar formação básica comum e respeito aos valores culturais e artísticos, nacionais e regionais. $\S 2^{\circ}-\mathrm{O}$ ensino fundamental regular será ministrado em língua portuguesa, assegurada às comunidades indígenas também a utilização de suas línguas maternas e processos próprios de aprendizagem.

Deste modo, as reflexões e ganhos voltados para a cidadania indígena, incluindo as inquietações de convivência na diferença e uma educação distinta dos padrões não índio, voltadas para o respeito a diversidade sociocultural são de extrema relevância. Assim, a educação escolar indígena pós 1988, traz alguns aspectos legais e novas direções das ações educacionais desenvolvidas para os povos indígenas. Acautelados pela igreja e posteriormente pelo SPI e Funai, porém nos anos de 1990, a educação escolar indígena passa a ser responsabilidade do Ministério da Educação (MEC), em decorrência do decreto $\mathrm{n}^{\mathrm{o}} 26$ 4/02/1991, que retira essa responsabilidade da Funai. A educação passa a ter um caráter fundamental na constituição da identidade da história social dos povos nativos brasileiros, perpetrando a legislação específica que legitima sua diferença étnica dentro do território nacional, assegurando-lhes o uso de suas línguas maternas, culturas próprias e de seus territórios tradicionais. (GRUPIONI, 2014).

Dentre as leis que asseguraram esses ganhos educacionais teve-se a Lei de Diretrizes de Bases da Educação Nacional n ${ }^{\circ}$ 9.394/96 (LDBEN). Essa lei é o principal efeito da CF/88, estabelecendo os direcionamentos educacionais para todos os seguimentos (BRASIL, 1988). A LDB/96 desdobra os pressupostos enunciados na Constituição e reconhece, de maneira objetiva, que a sociodiversidade precisa ser trabalhada nas escolas. O art. 26 da LDB/96 aponta para a necessidade dos currículos da educação básica serem fundamentados nas mesmas bases 
nacionais, mas sem desconsiderar uma parte diversificada, demandada pelas características regionais e locais da sociedade, das culturas, da economia e da clientela (MARCON, 2010).

Nesse aspecto, o art. 79 da LDB/96 versa sobre o apoio técnico e financeiro aos sistemas de ensino no fornecimento da educação intercultural aos nativos, desenvolvendo programas integrados de ensino e pesquisa, dispondo do comprometimento em manter programas de formação para os professores indígenas, o desenvolvimento de currículos específicos e elaboração de material didático próprio dentro da realidade educacional nativa (BARÃO, 2008). Na Lei 9.394/96, a partir do art. $8^{\circ}$ consta o estabelecimento dos principais critérios dessa nova proposta direcionada a educação indígena no Brasil a qual expõe ser fundamental:

1 - proporcionar aos índios, suas comunidades e povos, a recuperação de suas memórias históricas; a reafirmação de suas identidades étnicas; a valorização de suas línguas e ciências; 11 - garantir aos índios, suas comunidades e povos, o acesso às informações, conhecimentos técnicos e científicos da sociedade nacional e demais sociedades indígenas e não-índias.

Assim sendo, torna-se viável o entendimento de que as demandas educacionais indígenas mais urgentes, voltadas a representação de sua cultura, estão presentes não só na legislação maior brasileira como na legislação escolar, evidenciando os caminhos positivos da luta e do movimento dos povos indígenas, o que não esconde a espantosa distância entre a teoria e a prática - os descaminhos, já que a realidade das aldeias e de suas escolas ainda necessitam de muita atenção para se encaixarem concretamente aos padrões sociais indígenas desejáveis.

Em 1998 foi criado o Referencial Curricular para as Escolas Indígenas (Rcnei) como parte integrante da série Parâmetros Curriculares Nacionais, elaborados pelo Ministério da Educação e do Desporto (BRASIL, 1998). O Rcnei teve o objetivo de cumprir a intensa tarefa, em caráter inédito no país, de apresentar ideias básicas e propostas de trabalho para as adjacentes áreas do conhecimento e para cada ciclo escolar inseridas no ensino fundamental das escolas indígenas. Este documento foi indutor e guia de novas práticas que contou com a participação de especialistas, técnicos e professores índios em sua formulação. Seu conteúdo é longo e detalhado, com considerações gerais sobre a educação escolar indígena, quer através da fundamentação histórica, jurídica, antropológica e pedagógica, base sustentacional da escola indígena intercultural e diferenciada dos padrões não-índios, quer através de propostas de trabalhos, por áreas do conhecimento, que aceitem a construção de um currículo específico e conexo a realidade vivida por cada comunidade nativa (GRUPIONI, 2014).

Em 1999 o Conselho Nacional de Educação (CNE) e a Câmara de Educação Básica (CEB) aprovaram o Parecer 14 que trata das Diretrizes Curriculares Nacionais da Educação 
Escolar Indígena (MARCON, 2010). Dentre as questões tratadas no Parecer 14, encontra-se a criação da Categoria Escola Indígena; as responsabilidades administrativas; a formação dos professores indígenas; o currículo de educação indígena e sua flexibilização; as formas de funcionamento e a contratação de professores indígenas. Assim, este Parecer tem por desígnio a contribuição para que os povos indígenas tenham assegurado o direito a uma educação de qualidade, que respeite e valorize seus conhecimentos e saberes tradicionais e permita que tenham acesso a conhecimentos universais, de forma a participarem ativamente como cidadãos plenos do país (BRASIL, 1999).

Em 09 de janeiro de 2001 foi aprovado o Plano Nacional de Educação (PNE) pela Lei $\mathrm{n}^{\circ} 10.172$, que nasce com o propósito de durar dez anos, este apresenta um capítulo inteiro sobre a educação escolar indígena, devidamente divido em três momentos: o primeiro apresenta um breve diagnóstico de como tem acontecido a oferta da educação escolar aos povos indígenas. O segundo, expõe as diretrizes para a educação escolar indígena e o terceiro, apresenta os objetivos e metas que deverão ser atingidas, a curto e a longo prazo.

Entre os objetivos e metas previstos no PNE destacam-se a universalização da oferta de programas educacionais aos povos indígenas para todas as séries do ensino fundamental, garantia de autonomia para as escolas indígenas, tanto no que se refere ao Projeto Político Pedagógico quanto ao uso de recursos financeiros. O PNE prediz ainda, a concepção de programas exclusivos para atender às escolas indígenas, bem como a criação de linhas de financiamento para a prática dos programas de educação em áreas. Estabelece que a União em coparticipação com os Estados precisa prover com equipamento didático-pedagógico básico essas escolas, contendo bibliotecas, videotecas e materiais de apoio para auxílio ao desenvolvimento da educação.

Portanto, estas leis, foram preponderantes para fundamentar e moldar a educação indígena, uma vez que destacaram a importância de um ensino escolar diferenciado para esses povos e também por apreciar suas tradições e culturas enquanto necessárias para o seu desenvolvimento social, oportunizando a participação indígena nos direcionamentos de todo processo educativo das aldeias, caracterizando a política indigenista em um novo paradigma: o participativo, com o intuito de "superação definitiva" do caráter de tutela ao qual os povos indígenas estiveram sujeitos desde o século XVI.

\section{OS DESDOBRAMENTOS DO MOVIMENTO EDUCACIONAL INDÍGENA NO ESTADO DO AMAPÁ}


Os desdobramentos dessa história de luta dos povos indígenas no Brasil por uma educação diferenciada podem ser verificados no estado do Amapá, nas medidas adotadas pela Secretaria de Estado da Educação (Seed) voltadas para a Escola Indígena e ainda pela implantação do Curso Intercultural Indígena na Universidade Federal do Amapá (Unifap). Dessa forma, a educação escolar implantada para os indígenas do Amapá e Norte do Pará a partir de 2002, ocorreu devido as determinações do MEC e da Portaria Interministerial do Ministério da Justiça no 559 de 16/04/1991, que constituiu o Conselho Estadual de Educação (CEE) pela Resolução $n^{\circ}$ 068/2002. Estes documentos fixaram normas para a criação e funcionamento das escolas indígenas, autorização e reconhecimento de cursos na educação básica do Amapá, considerando que este Estado é o responsável pela educação escolar destes povos (SILVA e BASTOS, 2013).

Assim as políticas educacionais para os indígenas no Amapá delinearam-se em atendimento a Portaria 559/91 do MJ/MEC que criou os Núcleos de Educação Escolar Indígena - Nei - nas secretarias Estaduais de Educação, de caráter interinstitucional com representações de entidades indígenas e com ação na educação escolar indígena. Essa portaria deliberou como prioridade o aperfeiçoamento constante de professores índios e de pessoal técnico das instituições para o exercício pedagógico, recomendando que os professores índios precisariam receber o mesmo pagamento dos demais professores. Além disso, são postas as condições para a regulamentação das "Escolas Indígenas" no que se acena o calendário escolar, metodologia e avaliação de materiais didáticos adequados à realidade sociocultural (BRASIL, 1999, p. 9).

O Núcleo de Educação Escolar Indígena do estado do Amapá está vinculado à Seed/AP, pautado em leis de nível nacional, como a Constituição de 1988, nos art. 210 e 215 e cap. III, art. 98; no parecer 014, que dá origem a Resolução 03/994 vigente até 2012, que quando reformulada origina a Resolução 05/12, que está em vigor até os dias de hoje. A lei de âmbito estadual que sustenta a implantação do Nei é a 068/02, que dispõe do Conselho de Educação Estadual $^{5}$. Quando a responsabilidade da educação escolar indígena passou para o Nei, as escolas indígenas eram atendidas por professores não índios, inicialmente enviados da

\footnotetext{
${ }^{4}$ Esta resolução é de maior importância para a educação escolar indígena no país, pois estabelece as Diretrizes Nacionais para a organização, estrutura e funcionamento das escolas indígenas. Define as competências da União, dos Estados e Municípios nas ações voltadas ás escolas indígenas: administração, das escolas, formação de professores, elaboração de material didático. Também define as esferas de regulamentação dos projetos pedagógicos e regimentos escolares das escolas indígenas (PROPOSTA CURRICULAR KARIPUNA E GALIBI-MARWORNO, 2003, p. 7).

${ }^{5}$ Todas as informações sobre Nei foram adquiridas com a pedagoga deste setor no ano de 2015. As informações foram devidamente registradas e redirecionadas para este trabalho.
} 
secretaria e depois pelo Sistema de Organização Modular de Ensino (Some) ${ }^{6}$, com seus professores atendendo o segundo seguimento do ensino fundamental.

O Nei iniciou a discussão da matriz curricular indígena no ano de 2000, em meio a dois encontros nos quais foram avaliadas as possibilidades de implantação da Proposta Curricular Karipuna e Galibi-Marworno (PCKGM). As discussões contaram com a consultoria de Antonella Tissinari em julho de 2001, na aldeia de Kararumã e janeiro de 2002, na aldeia Manga e na cidade de Oiapoque. Os encontros evidenciaram que os povos Karipuna e GalibiMarworno desejavam com urgência uma escola de qualidade e que respeitasse a sua cultura local. Suas dúvidas e preocupações diziam respeito à busca de uma educação escolar que permitisse a participação social, política e econômica para além de suas aldeias, como poder cursar escolar nas cidades ou prosseguir estudos universitários (PCKGM, 2003, p. 3). A PCKGM foi apresentada e aprovada pelo CEE entre 2002/2003, no entanto, essa proposta não obteve sucesso devido à falta de acompanhamento técnico-pedagógico, ou seja, dificuldades da Seed em manter esse monitoramento e profissional técnico dentro das escolas nas aldeias.

Outra medida tomada pelo NEI, diante da necessidade de continuar mantendo o ensino escolar nas aldeias, foi a criação do Sistema de Organização Modular de Ensino Indígena Somei - entre 2006/2007, instituído pela Seed em atendimento as exigências das comunidades. Por este novo sistema foram enviados profissionais com mais sensibilidade e afinidade com as questões indígenas, assumindo a execução da docência de $5^{\mathrm{a}}$ à $8^{\mathrm{a}}$ séries (hoje do $6^{\circ}$ ao $9^{\circ}$ ano) e ensino médio. Os professores do Somei já atuam no Oiapoque, Amapari e está sendo implantado no Parque Indígena do Tumucumaque para as etnias dessa TI, na modalidade de Jovens e Adultos (EJA).

Em atenção as reivindicações, reconhecimento, manutenção da identidade cultural e valorização dos povos que aqui habitam, o Estado propôs o Programa de Etno-Educação Indígena do Estado do Amapá (programa decenal - 2003-2013), com a finalidade de implementar de forma sistemática e gradual a sua política educacional, atendendo os preceitos constitucionais do próprio Estado e a Resolução no 068/2002 - CEE. O objetivo do programa foi envolver as comunidades e organizações indígenas, assim como instituições não-indígenas na construção de uma educação específica, intercultural, bilíngue, comunitária e diferenciada,

\footnotetext{
${ }^{6}$ O Some foi implantado no estado do Amapá em caráter experimental, em 1986 e em 2005 foi reestruturado, permanecendo até o momento atual para atender às necessidades educacionais e garantir o ensino sistemático à zona rural (localidade de fácil e difícil acesso) do Estado. Esse sistema foi criado pela dificuldade em oferecer professores formados em 12 disciplinas para alunos de pequenas comunidades afastadas dos grandes centros urbanos. Nesse modelo, em vez dos estudantes se mudarem, são os professores que viajam para atendê-los em suas comunidades. (Informações coletadas no Nei, no ano de 2015).
}

LCANOA DO TEMPO - O movimento educacional indígena no Brasil e seu desdobramento no Amapá (1988-2002): caminhos e descaminhos. 
em que fosse possível ouvir as múltiplas vozes e respeitar a pluralidade de pensamento dos diversos atores sociais. As Diretrizes Pedagógicas do Programa procuraram subsidiar a educação escolar dos povos nativos, afiançada em bases consistentes dos novos modelos de educação, apropriados para propagar as concepções de cada povo, seus ideais humanos e sociais. Dessa forma, a sua estrutura, organização e funcionamento deveriam estar pautadas nas seguintes diretrizes, conforme o Nei/AP:

1.A educação escolar indígena deverá ter como característica: o bilinguismo; a interculturalidade; a especificidade; a diferença e o comunitarismo; 2 . Na organização e gestão da escola indígena deverá ser assegurada a efetiva participação da comunidade, bem como o respeito aos seus traços culturais; 3 . O ensino escolar deverá ser ministrado na língua materna da comunidade, em português, como segunda língua e em uma língua estrangeira moderna, como terceira língua (à escolha da comunidade); 4. A educação escolar indígena privilegiará o uso de metodologias que respeitem a concepção e o uso de práticas pedagógicas específicas de cada grupo indígena, valorizando a oralidade no processo de ensino e aprendizagem e as alternâncias de espaço; 5. A construção e o uso de materiais didático-pedagógicos considerarão o contexto sociocultural de cada etnia indígena; 6 . A organização do trabalho escolar respeitará o fluxo das atividades econômicas, culturais e religiosas, independente do ano civil; 7. O calendário escolar será diversificado, ajustando-se às condições especificidades próprias de cada comunidade. 8. Os (as) professores (as) atuantes em área deverão ser indígenas bilíngues (falantes da língua materna do português) e ter formação específica para atuar na Educação Escolar Indígena; 9. O plano pedagógico de cada instituição deverá estabelecer as experiências educativas, os meios e os resultados a serem alcançados pela educação escolar não permitindo uma estrutura educacional diferente da desejada e necessária à população; 10. Aos índios, suas comunidades e povos deverão ser garantidos o acesso às informações, conhecimentos técnicos e científicos da sociedade envolvente e demais sociedades indígenas e não índias.

Pautado nesses direcionamentos o programa acima aludido propiciou a ampliação de uma política educacional adequada a realizar um conjunto de ações que "gerassem" a justiça social, o pleno exercício dos direitos indígenas e o usufruto dos bens culturais imprescindíveis ao bem-estar dos grupos étnicos regionais. No entanto, os sete subprogramas alocados no polo Uaçá - Galibili-Marworno, Galibi do Oiapoque, Karipuna e Palikur; no polo Tumucumaque Aparai -Waiana, Tiriyó - Kaxuyana; e polo Waiãpi - Waiãpi, contaram com ações de certa forma desconexas entre si, perpetuando as mesmas dificuldades de outrora para desenvolver e efetivar a educação diferenciada para esses povos.

Assim, mesmo perante os "esforços" da secretaria estadual de educação as exigências são constantes, haja vista que, até o momento, ainda não se tem claro qual escola deve ser ofertada aos índios e qual escola quer a sociedade brasileira para preencher os imperativos de sua população diversificada, ampla e tão cheia de margens e arestas não resolvidas. Todavia, 
destaca-se que as escolas existentes no Estado Amapá continuam em fase de construção, tanto pedagógica como em sua estrutura, pois as mudanças estabelecidas pela lei sugerem mais que transformações estruturais, indicam a necessidade de mudanças dos conteúdos e das metodologias a serem desenvolvidas junto as comunidades. Os caminhos estão apontados, mas se espera superar os descaminhos para concretizar a educação escolar indígena que é parte das luta e demanda ainda em aberto dessas populações.

Apesar das dificuldades, destaca-se a experiência de educação e formação de professores indígenas no nível superior no Amapá. Os pleitos educacionais dos povos indígenas foram apresentados a Unifap, que no ano de 2007 implanta o curso com destino à formação em nível superior de professores indígena (Informações obtidas no Projeto Político Pedagógico do Curso de Licenciatura Intercultural Indígena-PPP/2005).

Nesse sentido, a porta de acesso de indígenas ao ensino superior, destinado a formação em cursos de Licenciaturas para as comunidades contempladas dentro do Estado do Amapá e Norte do Pará, faz parte de diversos projetos que estão em movimento no Brasil, desde a instituição dos dispositivos legais para a política educacional pela $\mathrm{CF} / 88$ e suas leis subsequentes. O curso é resultado ainda do movimento e organização dos povos indígenas da região, com apoio de várias organizações governamentais, não governamentais e pesquisadores (PPP, 2005).

O Curso Intercultural Indígena está organizado em duas partes: formação geral (com temas contextuais de história indígena do Amapá, direitos territoriais, linguística e cultura e fundamentos pedagógicos da educação escolar Indígena) e formação específica para habilitação, contemplando as seguintes áreas do conhecimento: Ciências Humanas ${ }^{7}$, Linguagens e Códigos, Ciências Exatas e da Natureza. O ensino de História contribui com a formação de professores indígenas dialogando com as demais disciplinas das Ciências Humanas. O objetivo do curso é assegurar a formação de professores indígenas para a Educação Básica, prioritariamente das escolas indígenas do Amapá e Norte do Pará (PPP, 2005).

Portanto, a figura do professor indígena passa a ser priorizada nas discussões sobre acesso ao ensino superior, considerando a acuidade que carrega a Educação Básica para a autodeterminação dos povos indígenas. Sob essa ótica, os profissionais da educação indígena passam a ser formados nos parâmetros de valorização da sua pluralidade étnica e cultural, bem como devem ser capacitados para a implementação de propostas curriculares específicas para

\footnotetext{
${ }^{7}$ Nas Ciências Humanas, também, situam-se as áreas de Geografia, Filosofia, Ciências Sociais e Antropologia, Arqueologia, Ciência Política, Linguística, Direito, Letras e Artes.
} 
cada comunidade ou escola. De tal modo, buscou-se de maneira simples apresentar a sucinta compreensão desenvolvida dos desdobramentos do movimento nacional indígena no estado do Amapá em prol de uma educação escolar que respeite os seus múltiplos significados culturais e proporcione não mais o seu extermínio, nem a integração e interação das comunidades indígenas na sociedade, mas que possibilite a participação dos mesmos, enquanto sujeitos históricos ativos de todo o processo de construção e consolidação histórica, política, social e cultural do nosso país.

\section{CONSIDERAÇÕES FINAIS}

Baseado nos documentos analisados, constata-se que as leis promulgadas pós 1988, são de extrema relevância para a apreensão dos protótipos em que a educação indígena se encontra, em nível nacional e local. O índio já não mais incorpora a figura do invasor, mas sim a de um sujeito com direitos que faz parte da nação brasileira e que dela deve participar ativamente.

No entanto, não se pode escamotear as dificuldades encontradas pelas populações nativas para consolidar e fazer acontecer a educação escolar que eles tanto esperam, devido a problemas estruturais, de acesso, do quadro cada vez mais burocratizado das práticas para a formação de professores indígenas, além das formas de ingresso das instituições escolar dentro dos padrões estabelecidos pela lei. Essas questões confirmam que após a C.F/88 e com a promulgação das leis seguintes, como a LDB/96, a escola pública foi para dentro das aldeias, mas não conseguiu adequar-se aos aspectos particulares de identidade dessas sociedades, respeitando a cultura e as crenças das comunidades indígenas.

Assim, tem-se a compreensão de que a educação proporcionada aos indígenas deve garantir o reestabelecimento e valorização da sua cultura e evidenciar os valores que carregam, uma vez que todos os integrantes dessa nação, indígenas ou não, devem respeitar aqueles que de fato foram os primeiros habitantes do país, cuja história e crenças trouxeram significativas contribuições para construção da cultura brasileira. Os direitos e respeito aos indígenas devem sair do papel e concretizar-se em reverência a sua condição de sujeito histórico precursor das terras brasileiras. Os caminhos foram abertos pela luta indígena, mas cabe a todo povo brasileiro vencer os descaminhos da discriminação, do preconceito e marginalização a que as populações indígenas em muito estão fadadas

Recebido em: 18/07/2018 Aceito em: 19/12/2018 


\section{REFÊRENCIAS BIBLIOGRÁFICAS}

BARÃO, Vanderlise Machado. Educação Indígena: um breve histórico constitucional e propostas para uma escola diferenciada. Biblos, Rio Grande, 22 (2): 83-94, 2008. Disponível em: <http://www.brapci.ufpr.br/download.php?ddo=10262 > Acesso em 23 jul. 2014, $18: 24: 45$.

BELFOR, Lúcia Fernanda Inácio. A proteção dos conhecimentos tradicionais dos povos indígenas, em face da convenção sobre diversidade biológica. 2006. 139 f. Dissertação (Mestrado) - Universidade de Brasília - UNB, Faculdade de Direito. Brasília, 2006.

BELLO, José Luiz de Paiva. Educação no Brasil: a história das rupturas. Pedagogia em Foco, Rio de Janeiro, 2001. Disponível em: <http://www.pedagogiaemfoco.br/heb14.htm>. Acesso em: 27 ago. 2014, 14:25:45.

BRASIL. Constituição da República Federativa do Brasil de 1988. 1988. Brasília - DF. 2012.

Lei $\mathrm{n}^{\circ}$ 9.394, de 20 de dezembro de 1996. Estabelece as diretrizes e bases da educação nacional. Disponível em: <http://www.planalto.gov.br/ccivil_03/Leis/L9394.htm>. Acesso em: 03 jun. 2015, 09:34:13.

Referencial Curricular Nacional das Escolas indígenas. Ministério da Educação e do Desporto, Secretaria de Educação Fundamental. - Brasília: MEC/SEF, 1998.

Parecer $\mathrm{n}^{\mathbf{0}}$ 14. Diretrizes Curriculares Nacionais da Educação Escolar Indígena.

- Brasília, DF, 1999.

Lei no 10.172, de 9 de janeiro de 2001. Aprova o Plano Nacional de Educação e dá outras providências. Disponível em: <http://www.planalto.gov.br/ccivil_03/Leis/Leis_2001/110172.htm>. Acesso em: 03 jun. 2015, 13:24:55.

CUNHA, Manuela Carneiro da. Índios no Brasil: história, direitos e cidadania. $1^{\text {a }}$ ed. - São Paulo: Claro Enigma, 2012.

EVANGELISTA, Olinda. Apontamentos para o trabalho com documentos de política educacional. I Colóquio A Pesquisa em Trabalho, educação e Políticas Educacionais. Belém: UFPA, 2009. Disponível em: <http://pt.scribd.com/doc/211971320/texto-Olinda-PDF.>. Acesso em: 10 set. 2014, 22:23:14.

GRUPIONI, Luís Donizete Benzi. Políticas indigenistas: educação Escolar Indígena, 2014. Disponível em: <http://pib.socioambiental.org/pt/c/politicas-indigenistas-educacao->. Acesso em: 23 jul. 2014, 18:34:55.

MARCON, Telmo. Educação Indígena diferenciada bilíngue e intercultural no contexto das políticas afirmativas. Visão global, Joaçaba, v. 13, n. 1, p. 97-118, jan./jun. 2010.

MUNDURUKU, Daniel. O caráter educativo do movimento indígena brasileiro (19701990). - São Paulo: Paulinas, 2012. 
OLIVEIRA, João Pacheco de; FREIRE, Carlos Augusto da Rocha. A presença indígena na formação do Brasil. Secretaria de Educação Continuada, Alfabetização e Diversidade; LACED/Museu Nacional, 2006.

PROPOSTA CURRICULAR KARIPUNA E GALIBI-MARWORNO. Proposta Curricular para as Escolas Indígenas Karipuna e Galibi-Marworno: Atualização em 2002. Amapá, 2003.

RIBEIRO, Darcy. Os índios e a civilização: a integração das populações indígenas no Brasil Moderno. São Paulo: Companhia das Letras, 2004.

SAVIANI, Dermeval. História das ideias pedagógicas no Brasil. Campinas, SP: Autores Associados, 2013.

SILVA, Alex Alexandre do Rosário da; BASTOS, Cecília Maria Chaves Brito.

Implementação de Políticas Públicas de Educação Escolar para Indígenas ApalaiWaiana do Norte do Pará - (2002-2012). 2013. 22 f. Artigo (Graduação em História) -

UNIVERSIDADE FEDERAL DO AMAPÁ. Projeto político Pedagógico do Curso de Licenciatura Escolar Indígena. Amapá: UNIFAP, 2005. 